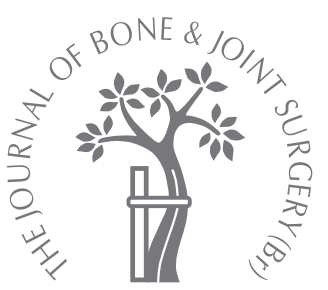

V. Wylde,

A. Blom,

P. Dieppe,

S. Hewlett,

I. Learmonth

From Southmead

Hospital, Bristol,

England

\title{
Return to sport after joint replacement
}

Our aim was to determine the pre-operative sporting profiles of patients undergoing primary joint replacement and to establish if they were able to return to sport after surgery. A postal survey was completed by 2085 patients between one and three years after operation. They had undergone one of five operations, namely total hip replacement, hip resurfacing, total knee replacement, unicompartmental knee replacement or patellar resurfacing. In the three years before operation $726(34.8 \%)$ patients were participating in sport, the most common being swimming, walking and golf. A total of $446(61.4 \%)$ had returned to their sporting activities by one to three years after operation and $192(26.4 \%)$ were unable to do so because of their joint replacement, with the most common reason being pain. The largest decline was in high-impact sports including badminton, tennis and dancing. After controlling for the influence of age and gender, there was no significant difference in the rate of return to sport according to the type of operation.

II V. Wylde, BSc, Research Assistant

A. Blom, MD, FRCS, PhD, Consultant Orthopaedic Surgeon

I. Learmonth, FRCS, FRCS(Ed), FCS(SA)Orth, Professor of Orthopaedic Surgery

University of Bristol, Bristol Implant Research Centre, Avon Orthopaedic Centre

Southmead Hospital, Westbury-on-Trym, Bristol BS10 5NB, UK.

= P. Dieppe, MD, FRCP, FFPH Honorary Professor of Musculoskeletal Sciences Nuffield Department of Orthopaedic Surgery University of Oxford, Nuffield Orthopaedic Centre, Windmill Road, Headington, Oxford OX3 7LD, UK.

In. Hewlett, RN, MA, PhD, Professor of Rheumatology and Nursing

University of the West of England,

Academic Rheumatology Unit Bristol Royal Infirmary, Marlborough Street, Bristol BS2 8HW, UK.

Correspondence should be sent to Miss V. Wylde; e-mail: V.Wylde@bristol.ac.uk

(C)2008 British Editorial Society of Bone and Joint Surgery doi:10.1302/0301-620X.90B7. $20614 \$ 2.00$

$J$ Bone Joint Surg $[\mathrm{Br}]$ 2008;90-B:920-3.

Received 13 December 2007;

Accepted 14 February 2008
Advances in surgical techniques have been accompanied by increasing patient expectations and there is now a demand for joint replacement to allow a return to higher function activities, such as sports. The ability to return to sporting activities is important to some patients and if such expectations are not met, there may be dissatisfaction with the outcome of technically successful surgery. ${ }^{1,2}$

It is predicted that the demand for total hip replacement (THR) and total knee replacement (TKR) will grow by $174 \%$ and $673 \%$, respectively, between 2005 and $2030,{ }^{3}$ because of changing demographics and wider indications. ${ }^{4}$ With the increase in joint replacement and the rise in expectations, it is important to determine if these procedures allow patients to return to sporting activities.

Although previous studies have explored participation in sport after joint replacement, ${ }^{5-13}$ none has compared the rate of return to sport after a range of such procedures in the lower limb. We have undertaken a cross-sectional postal survey to determine the pre-operative sporting profiles of patients undergoing either primary THR, hip resurfacing, TKR, unicompartmental knee replacement (UKR) or patellar resurfacing and to establish if these procedures allow them to return to sporting activities.

\section{Patients and Methods}

All living patients who had undergone a primary THR, hip resurfacing, TKR, UKR or patellar resurfacing at the Avon Orthopaedic Centre between April 2004 and April 2006 were included in the survey. Ethical approval had been obtained from the Local Research Ethics Committee.

Questionnaires were sent to 3125 patients, of whom $2085(66.7 \%)$ responded. Of these, 911 had THR, 157 hip resurfacing, 866 TKR, 100 UKR and 51 patellar resurfacing.

We included patients in whom the operation had been performed between one and three years previously because the short-term outcome has been shown to reflect the longer-term result. ${ }^{14,15}$ Patients who had multiple primary joint replacements were sent a questionnaire about one joint only to reduce the participation burden and to ensure that they were not over-represented in the study. The joint included was the first to be replaced during the period of study. If simultaneous replacements were performed, the side was chosen at random.

The patients were asked if they had taken part in any sport in the three years before their joint replacement. If they answered 'yes' they were asked to list their sporting activities. They were then asked whether they had been able to return to any sporting activities post- 
Table I. Clinical details, post-operative pain and function scores and participation in sport

\begin{tabular}{|c|c|c|c|c|c|c|}
\hline & Overall & THR $^{*}$ & Hip resurfacing & $\mathrm{TKR}^{\dagger}$ & $\mathrm{UKR}^{\ddagger}$ & Patellar resurfacing \\
\hline Number of patients & 2085 & 911 & 157 & 866 & 100 & 51 \\
\hline \multicolumn{7}{|l|}{ Gender (\%) } \\
\hline Male:female & $42: 58$ & $37: 63$ & $71: 29$ & $41: 59$ & $48: 52$ & 23:77 \\
\hline Mean age at surgery in yrs (range) & $67.3(15$ to 94$)$ & 68.2 (15 to 94$)$ & $52.2(25$ to 72$)$ & 69.6 ( 26 to 93 ) & 66.0 (45 to 88$)$ & 56.0 ( 25 to 80$)$ \\
\hline \multicolumn{7}{|l|}{ Mean post-operative WOMAC W $^{\S}$ score (SD) } \\
\hline Pain & $85.2(19.7)$ & $88.9(17.6)$ & $92.8(13.9)$ & $81.5(20.8)$ & $81.6(19.3)$ & $66.8(26.2)$ \\
\hline Function & $79.9(20.6)$ & $82.6(19.0)$ & $89.6(16.0)$ & $76.3(21.4)$ & $79.1(20.5)$ & $64.3(26.5)$ \\
\hline \multicolumn{7}{|l|}{ Number of patients (\%) } \\
\hline Active in sport pre-operatively & $726(34.8)$ & $318(34.9)$ & $101(64.3)$ & $253(29.2)$ & $36(36)$ & $18(35.3)$ \\
\hline $\begin{array}{l}\text { Unable to return to sport post-opera- } \\
\text { tively because of joint replacement }\end{array}$ & $192(26.4)$ & $84(26.4)$ & $23(22.7)$ & $68(26.9)$ & $9(25)$ & $8(44.4)$ \\
\hline \multicolumn{7}{|l|}{$\dagger T K R$, total knee replacement } \\
\hline \multicolumn{7}{|l|}{ ‡ UKR, unicompartmental knee replacement } \\
\hline
\end{tabular}

operatively. If they answered 'no' they were asked to provide the reasons why.

Use of the joint was assessed using the Western Ontario McMasters Osteoarthritis Index (WOMAC) pain and function scales ${ }^{16}$ which judges pain during five different activities and functional limitations on performing 18 activities of daily living.

Statistical analysis. The chi-squared test was used to compare differences in the rates of pre-operative participation in sport with the clinical details and type of operation. A logistic regression model was used to determine the clinical variables which were significantly correlated with a return to sport and whether, after adjustment for these factors, there was a difference in the rate of return to sport according to the type of operation.

\section{Results}

The details of the patients, their WOMAC scores and their pre- and post-operative participation in sport are shown in Table I.

In the three years before their joint replacement, 726 patients $(34.8 \%)$ participated in one or more sporting activities (Table I). The ten most common are shown in Figure 1. In total, 1452 patients participated in sports performing a mean number of two (0 to 6) sporting activities each.

Pre-operatively, participation in sport declined with age ( $\mathrm{p}<0.001$; Fig. 2 ) and was significantly higher in men than in women $(43 \%$ vs $29 \%$ respectively; $\mathrm{p}<0.001)$. There was also a significant difference in pre-operative participation according to the type of operation $(\mathrm{p}<0.001$; Table I). Patients who went on to have hip resurfacing were the most active pre-operatively, with $64.3 \%$ participating in one or more sports. The lowest rate of participation $(29.2 \%)$ was in patients who had a TKR.
Of the 726 patients who participated in sports pre-operatively, $446(61.4 \%)$ had returned to their pre-operative activities by one to three years after operation. Of the 280 $(38.6 \%)$ patients who had been unable to return to sport, $16(5.7 \%)$ gave no reason, $72(25.7 \%)$ indicated reasons unrelated to the joint replacement such as arthritis in other joints, age, other general health problems or loss of interest, and $192(68.6 \%)$ had not resumed participation because of their joint replacement. These latter patients represented $26.4 \%$ of those who had undertaken sports pre-operatively. They generated 205 reasons as to why they were unable to return to these activities. The five most common are given in Table II, with pain the most frequent.

In order to determine which activities had the largest post-operative decline in participation, non-return was analysed for those activities in which at least 30 patients had participated pre-operatively. The largest decline was in high-impact sports, with 19 of 37 patients $(51.3 \%)$ being unable to return to badminton, 15 of $40(37.5 \%)$ to tennis and 23 of $72(31.9 \%)$ to dancing.

The percentage of patients who were unable to return to sport after each type of operation is given in Table I, and Table III shows the results from a logistic regression model including age, gender and type of operation. Whereas age had no significant effect on return to sport, the odds for men returning to sport were 1.8 times greater than those for women $(p<0.01)$. There was no significant difference in a return to sport according to the type of operation.

\section{Discussion}

In the three years before surgery, $34.8 \%$ of patients participated in one or more sports. This agrees with previous findings in a study from Germany in which $36 \%$ of THR patients and $42 \%$ of TKR patients participated in sporting 


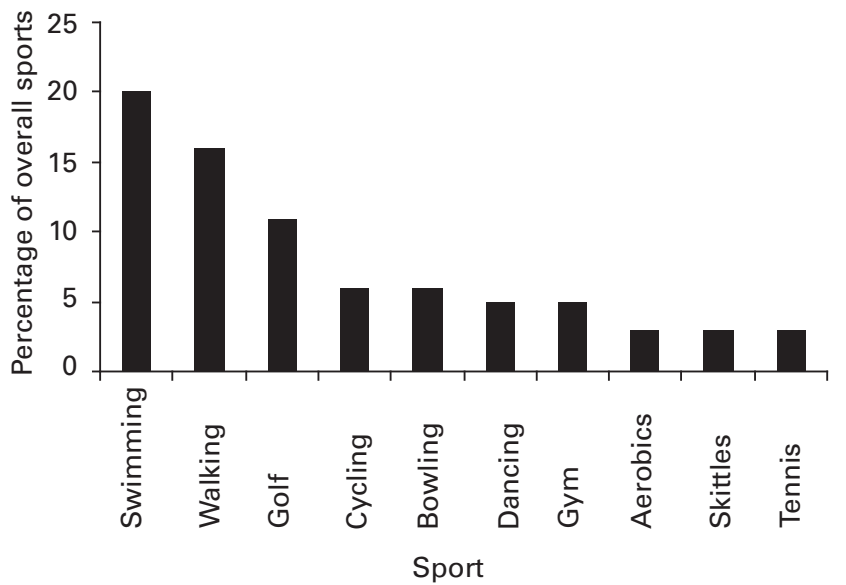

Fig. 1

Bar chart showing the ten most common pre-operative sporting activities.

Table II. Five most common reasons generated by patients for an inability to return to sport because of the replaced joint, ordered by overall percentage

\begin{tabular}{lll}
\hline & $\begin{array}{l}\text { Number of } \\
\text { patients }\end{array}$ & $\begin{array}{l}\text { Overall } \\
\text { percentage* }\end{array}$ \\
\hline Pain & 55 & 27 \\
Unable to do required movements & 53 & 26 \\
Medical advice & 25 & 12 \\
Fear of damaging joint & 21 & 10 \\
Lack of confidence & 14 & 7 \\
\hline * percentages are calculated out of 205, the number of reasons \\
generated for an inability to return to sport because of the replaced \\
joint
\end{tabular}

activities at the time of surgery. ${ }^{10}$ However, these rates of participation were lower than those noted from Australia by Chatterji et al, ${ }^{5,6}$ who found that $80 \%$ of THR patients and $85 \%$ of TKR patients took part in sports in the year before operation. These higher rates of sports participation in Australia may be explained by the fact that the Australian participants were less disabled pre-operatively than their counterparts in the United Kingdom ${ }^{17}$ and therefore were more able to return to sport earlier. There may also be cultural differences.

The most common pre-operative sports were low-impact activities including swimming, walking and golf. Other studies have also shown that the sports performed most frequently before operation by patients undergoing joint replacement include cycling, walking, bowling and swimming., ${ }^{5,6,10,11}$

Age was the most important factor in participation in sport before operation. In our study, those who were to have hip resurfacing were the youngest and the most active group, with $64.3 \%$ participating in one or more sports. Even higher rates of sports participation have been described in these patients, with $95 \%$ participating in one or more sports before operation. ${ }^{12}$

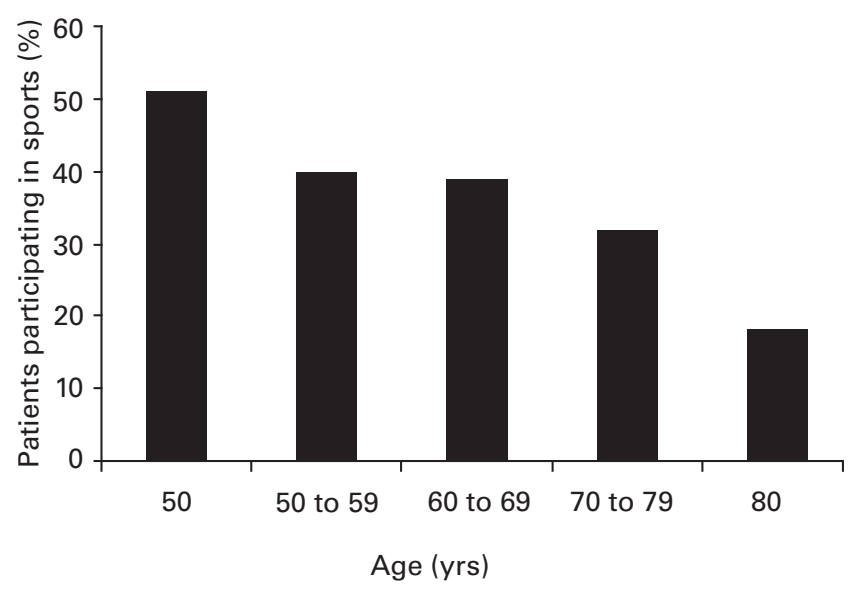

Fig. 2

Bar chart showing the percentage of patients participating in sport preoperatively by age group.

Table III. Logistic regression of a return to sports after joint replacement

\begin{tabular}{|c|c|c|}
\hline Variable & B & Exponentiation of $ß$ \\
\hline \multicolumn{3}{|l|}{ Age $(y r s)^{*}$} \\
\hline 49 and under & -0.260 & 0.771 \\
\hline 50 to 59 & -0.069 & 0.933 \\
\hline 60 to 69 & 0.311 & 1.365 \\
\hline 70 to 79 & 0.105 & 1.111 \\
\hline \multicolumn{3}{|l|}{ Gender $^{\dagger}$} \\
\hline Male & $0.580^{\ddagger}$ & 1.786 \\
\hline \multicolumn{3}{|l|}{ Type of operation ${ }^{\S}$} \\
\hline Total knee replacement & -0.332 & 0.731 \\
\hline Total hip replacement & -0.314 & 0.717 \\
\hline $\begin{array}{l}\text { Unicompartmental knee } \\
\text { replacement }\end{array}$ & -0.284 & 0.753 \\
\hline Patellar resurfacing & -0.787 & 0.455 \\
\hline \multicolumn{3}{|l|}{ * Base: 80 years or older } \\
\hline \multicolumn{3}{|l|}{ † Base: female } \\
\hline \multicolumn{3}{|l|}{$\ddagger p<0.01$} \\
\hline$\S$ Base: hip resurfacing & & \\
\hline
\end{tabular}

The sports which showed the greatest reduction in participation were badminton, tennis and dancing. Several other studies have observed a shift from participation in high-impact sports, such as jogging and tennis, $, 5,11,12$ and an increase in low-impact sports such as walking and aquaaerobics after surgery. ${ }^{5,6}$ This may have been due to a combination of advice from surgeons to avoid high-impact sports ${ }^{18}$ and encouragement by physiotherapists to participate in low-impact activities to improve muscle strength as part of post-operative rehabilitation.

After controlling for age and gender, there was no significant difference in the rate of return to sport according to the type of operation. In particular, the return after hip resurfacing was similar to that after THR, which suggests 
that hip resurfacing confers no advantage over conventional THR. It is therefore particularly important to inform these highly active patients as to the possibility of not being able to return to sport post-operatively.

There are some limitations to our study. First, it was retrospective and required patients to remember if they had participated in sports pre-operatively. Recall bias could have influenced the results. To minimise this, the recall period was limited to three years before operation rather than life-time participation in sport. However, because symptoms may have been present for a long time before joint replacement, some patients may have had to give up sport more than three years before surgery and therefore would not have been included. In addition, other factors, such as the body mass index, which could have influenced the rate of return to sport after joint replacement, were not considered and we did not assess the rate of uptake of new sports after joint replacement and how long it took patients to return to sport after surgery.

In conclusion, we found that $34.8 \%$ of patients were active in sport in the three years before joint replacement. At one to three years after operation, $26.4 \%$ of patients were unable to return to sport because of reasons related to the joint replacement, most commonly pain. After controlling for the effect of patient demographics, there was no significant difference in the rate of return to sport after THR, hip resurfacing, TKR, UKR and patellar resurfacing. It is important that surgeons discuss the probability of return to sport with patients before operation in order to obviate unrealistic expectations.

The consumables for this postal survey were funded by the North Bristol Trust Research and Development Small Grant Scheme.

The authors wish to thank S. Ayis for statistical support.

No benefits in any form have been received or will be received from a commercial party related directly or indirectly to the subject of this article.

\section{References}

1. Wylde V, Hewlett S, Learmonth ID, Cavendish VJ. Personal impact of disability in osteoarthritis: patient, professional and public values. Musculoskeletal Care 2006;4:15266.

2. Weiss JM, Noble PC, Conditt MA, et al. What functional activities are important to patients with knee replacements? Clin Orthop 2002;404:172-88.

3. Kurtz S, Ong K, Lau E, Mowat F, Halpern M. Projections of primary and revision hip and knee arthroplasty in the United States from 2005 to 2030. J Bone Joint Surg [Am]2007;89A:780-5.

4. Crowninshield RD, Rosenberg AG, Sporer SM. Changing demographics of patients with total joint replacement. Clin Orthop 2006;443:266-72.

5. Chatterii U, Ashworth MJ, Lewis PL, Dobson PJ. Effect of total hip arthroplasty on recreational and sporting activity. ANZ J Surg 2004;74:446-9.

6. Chatterii U, Ashworth MJ, Lewis PL, Dobson PJ. Effect of total knee arthroplasty on recreational and sporting activity. ANZ J Surg 2005;75:405-8.

7. Fisher N, Agarwal M, Reuben SF, Johnson DS, Turner PG. Sporting and physical activity following Oxford medial unicompartmental knee arthroplasty. Knee 2006;13:296300.

8. Healy WL, lorio R, Lemos MJ. Athletic activity after total knee arthroplasty. Clin Orthop 2000;380:65-71.

9. Healy WL, lorio R, Lemos MJ. Athletic activity after joint replacement. Am J Sports Med 2001;29:377-88.

10. Huch K, Müller KA, Stürmer T, et al. Sports activities 5 years after total knee or hip arthroplasty: the Ulm Osteoarthritis Study. Ann Rheum Dis 2005;64:1715-20.

11. Naal FD, Fischer M, Preuss A, et al. Return to sports and recreational activity after unicompartmental knee arthroplasty. Am J Sports Med 2007;35:1688-95.

12. Naal FD, Maffiuletti NA, Munzinger U, Hersche 0 . Sports after hip resurfacing arthroplasty. Am J Sports Med 2007;35:705-11.

13. Dubs L, Gschwend N, Munzinger U. Sport after total hip arthroplasty. Arch Orthop Trauma Surg 1983;101:161-9.

14. Heck DA, Robinson RL, Partridge CM, Lubitz RM, Freund DA. Patient outcomes after knee replacement. Clin Orthop 1998;356:93-110.

15. Lingard EA, Katz JN, Wright EA, Sledge CB, the Kinemax Outcomes Group. Predicting the outcomes of total knee arthroplasty. J Bone Joint Surg [Am] 2004;86-A:217986.

16. Bellamy N, Buchanan WW, Goldsmith CH, Campbell J, Stitt LW. Validation study of WOMAC: a health status instrument for measuring clinically important patient relevant outcomes to antirheumatic drug therapy in patients with osteoarthritis of the hip or knee. J Rheumatol 1988; 15:1833-40.

17. Lingard EA, Sledge CB, Learmonth ID, Kinemax Outcomes Group. Patient expectations regarding total knee arthroplasty: differences among the United States, United Kingdom, and Australia. J Bone Joint Surg [Am]2006;88-A:1201-7.

18. McGrory BJ, Stuart MJ, Sim FH. Participation in sports after hip and knee arthroplasty. review of literature and survey of surgeon preferences. Mayo Clin Proc 1995;70:342-8. 